\title{
EN BÚSQUEDA DE LA RACIONALIDAD PERDIDA: ALGUNOS DETERMINANTES DEL VOTO EN EL DISTRITO FEDERAL, BRASIL Searching for the lost rationality
}

\author{
Gláucio Ary DILlON SOARES \\ Instituto Universitário do Rio de Janeiro. University of Florida \\ soares7@bellsouth.net
}

BIBLID [1130-2887 (2001) 29, 81-107]

Fecha de recepción: septiembre del 2001

Fecha de aceptación y vesión final: octubre del 2001

RESUMEN: Las encuestas llevadas a cabo durante el régimen militar pusieron de manifiesto que las evaluaciones de diferentes políticas públicas correlacionan muy poco entre sí, son particularmente bajas entre analfabetos y encuestados con niveles educativos bajos, y no constituyen buenos predictores de la intención de voto y de las preferencias partidistas. Sin embargo, datos procedentes de una amplia encuesta domiciliar preelectoral en el Distrito Federal, con una muestra aleatoria estratificada, contradicen estos resultados; existe correlación entre evaluaciones de distintas políticas públicas, la magnitud de las correlaciones entre evaluaciones de políticas públicas no sigue un patrón de relación con los niveles educativos y constituyen una excelente predictor de las preferencias de voto para las elecciones a gobernador. Las disparidades que arrojan estos resultados pudieran ser resultado de cambios reales en la población a lo largo de los últimos quince años, a especificidades del Distrito Federal (niveles de renta per cápita más altos y uno de los más altos niveles educativos del país), a una elección en la que el candidato de la gobernación saliente compite contra un exgobernador, al énfasis de la campaña del gobernador saliente, a características del régimen militar o a una combinación de todas ellas. Cualquiera que sea la explicación, las elecciones de 1998 mostraron la existencia de una racionalidad que conecta la intención de voto con la evaluación de políticas públicas. No obstante, este vínculo pudiera ser específico y no generalizable a otros niveles electorales ni a preferencias partidistas.

Palabras clave: Elecciones, políticas públicas, elección racional, clases sociales, régimen autoritario, democracia.

ABSTRACT: Surveys carried out during the military regime have shown that the evaluation of different public policies have low correlations with each other, are particularly low among illiterates and poorly educated respondents and were poor predictors of voting intention and party preferences. However, data from a large pre-election poll, with a stratified random household sample in the Distrito Federal, contradict these findings. In this survey, evaluations of public policies cluster, yet are not "block and blind" answers, the magnitude of their inter-correlations does not follow educational lines, and the evaluations are excellent predictors of voting preference for governor. The disparities among these findings may result from real changes in the population During the last decade and a half, to specificities of the Distrito Federal (higher per capita income and one of the highest educational levels in the nation), to an election in which the incumbent governor ran against a former governor, to the campaign emphasis of the incumbent governor, who was running on his record, to characteristics of the military regime, or to combinations thereof. Regardless of the explanation that one may favor, the 1998 elections showed the existence of a rationality that linked voting intention to the evaluation of public policies. However, this linkage might be specific to this particular election, and not generalizable to other electoral levels or to party preferences.

Key words: Elections, Public policies, Rational choice, Social classes, Authoritarian regime, Democracy. 


\section{INTRODUCCIÓN ${ }^{1}$}

En Brasil, durante la dictadura, una serie de encuestas electorales, realizadas con la participación de algunos de los más destacados científicos políticos brasileños, revelaron una preocupante realidad: las evaluaciones de las cuestiones políticas nacionales (como diferente de estatales o municipales) más prominentes, que caracterizaran aquel régimen, tenían bajas correlaciones unas con las otras y también con las preferencias partidarias y las intenciones de voto. Las evaluaciones de los servicios públicos y de las políticas públicas relativas a las administraciones estatal y municipal tenían correlaciones todavía más bajas entre sí y casi nulas con las preferencias partidarias y con la intención de voto. Para los científicos políticos y sociales brasileños, ese hallazgo generó indagaciones y una gran preocupación: como el voto no estaba ligado al desempeño gubernamental, pasaba a ser electoralmente necesario hacer un buen gobierno. Los diagnósticos y pronósticos eran sombríos porque, sin "cobrança" no bay accountability (rendición de cuentas). Sin embargo, para los laicos, sobre todo los derechistas, esos resultados generaron certezas llenas de prejuicio: los electores brasileños eran "irracionales", particularmente los menos educados y, si pudiesen votar para presidente y gobernador, seleccionarían los mandatarios a partir de criterios emotivos, irracionales, víctimas fáciles de cualquier demagogo de esquina. Peor, la "cabeza" de los electores brasileños sería aleatoria: ellos no juntarían nada con nada, no habría estructura ${ }^{2}$, ni creencias ni actitudes. En este sentido, serían preideológicos y, con ello, la cultura política brasileña sería precívica. Si bien esas posiciones elitistas eran antiguas en el Brasil; los datos de esas correctas investigaciones vinieron a reforzarlas, en contra del ideario democrático de los investigadores.

En el municipio de São Paulo, en 1978, en el inicio de la etapa de la "distensão", Lamounier (1978) estudió las relaciones entre evaluaciones del desempeño del gobierno y las preferencias partidarias, por nivel educacional. Este autor usó cinco áreas de evaluaciones (atención médica en el INPS ${ }^{4}$; costo de vida; programa de casa propia a través del Banco Nacional de la Habitación; escuelas primarias y policía) y cuatro niveles educacionales (hasta primario completo; gimnasial; colegial y superior), lo que proporciona veinte combinaciones posibles. Los coeficientes de correlación 2, publicados por Lamounier, permiten observar que de los veinte coeficientes solamente cuatro eran significativos al nivel de 5\%; de esos cuatro, tres se referían a personas con educación universitaria. Solamente uno de los veinte coeficientes era superior a $0,3 \mathrm{y}$, con ello, la conclusión que se imponía era que:

1. Trabajo presentado a la $V^{a}$ Reunión de la Asociación Española de Ciencia Política (AECPA), realizado en Tenerife, en septiembre de 2001. El autor agradece los comentarios de varias personas.

2. Estructura, en el sentido de actitudes y creencias interrelacionadas.

3. La etapa de la "distensión" fue el período, bajo Geisel, en el cual la dictadura se ablandó, reanudándose algunos derechos civiles y políticos.

4. INPS es el servicio médico federal de Brasil, tratando, además, de la salud pública. 
- Las asociaciones entre las evaluaciones de políticas públicas y las preferencias partidarias eran irrelevantes en todos los niveles educacionales, excepto el superior, en el que, aún así, eran modestas.

Lamounier (1978) analizó, también, ocho áreas de opiniones político-institucionales atribuidas a los candidatos y sus correlaciones con las preferencias partidarias, controlando por los mismos niveles educacionales. De las 32 correlaciones, solamente tres, todas relativas al derecho a la huelga, eran estadísticamente significativas al nivel de $5 \%$ y ningún coeficiente alcanzó el 0,3 . Como diferente de las evaluaciones de las políticas públicas, ninguna de las correlaciones era significativa aún entre los entrevistados con nivel universitario. Esos resultados permitían concluir que:

- La percepción de, y las opiniones sobre, las posiciones político-institucionales de los candidatos eran irrelevantes para la preferencia partidaria, excepto la que se refiere al derecho de huelga.

Siguiendo las perspicaces observaciones de Wanderley Reis (1978), los investigadores separaron los datos relativos a nueve "grandes cuestiones" nacionales, siendo éstas investigadas por Lamounier de manera individual. En tiempos de dictadura, las grandes cuestiones nacionales son el fin de sus aspectos más duros. Comparativamente, en aquel momento, las demás cuestiones eran menores. El ejercicio fue productivo: de las 36 correlaciones, 14 eran significativas al 5\% (pero 22 no lo eran). Había solamente dos coeficientes superiores al 0,5 ; solamente cuatro eran $\exists 0,4$ y seis eran $\exists 0,3$.

La consistencia de esas evaluaciones, una vez más, varió con la educación de los entrevistados. En lo que concierne a "las grandes cuestiones", los entrevistados con nivel superior también eran los más consistentes. Sin embargo, la misma afirmación de que "o povo sabe votar e normalmente escolhe os melhores candidatos", no se correlacionaba con la preferencia partidaria en ninguno de los niveles educacionales analizados.

El minucioso estudio de Lamounier (1978) permite concluir que:

- Durante la dictadura, la mayoría de las asociaciones no era significativa en el nivel de $5 \%$ y $83 \%$ de los coeficientes eran inferiores a 0,3 .

- Sin embargo, llevando en consideración el carácter "suelto" de esas relaciones, la asociación de la preferencia partidaria con "las cuestiones nacionales" era más íntima que con la evaluación de las políticas públicas y que con la percepción de las posiciones institucionales de los candidatos.

- Las asociaciones eran más fuertes entre las personas con educación universitaria.

Algunas investigaciones, postdictadura, presentaron resultados semejantes a los encontrados en la serie de encuestas efectuada durante el período dictatorial. Luego, una vez en el proceso de redemocratización, en las elecciones de 1986, en São Paulo,

5. "El pueblo sabe votar y escoge a los mejores candidatos". 
Maria Judith de Brito Muszynski, analizando ocho áreas de políticas públicas relativas al Gobierno Federal, verificó que solamente cinco tenían correlación estadísticamente significativa con la intención de voto por Quércia, candidato al Gobierno del Estado por el mismo partido que dirigía el Gobierno Federal (PMDB) ${ }^{6}$. Las correlaciones eran bajas: la más alta era 0,26 y, de las ocho evaluaciones, solamente dos tenían correlaciones significativas con la intención de voto por el principal adversario, Paulo Maluf. La aprobación del gobernador Franco Montoro tenía una relación más íntima con la intención de voto del candidato del partido, Quércia, y con su más duro opositor, Maluf, que la aprobación al presidente Sarney ${ }^{7}$. La aprobación al nivel federal no era transferida para los candidatos del partido en los niveles estatal y municipal.

Las evaluaciones no formaron conglomerados apretados, sus interrelaciones eran sueltas. Además, ni el voto ni la preferencia partidaria dependían de las evaluaciones. Su influencia sobre el voto y la preferencia partidaria era pequeña. Algunos leerán esos resultados como prueba de que existía independencia entre la evaluación "global" del desempeño, las evaluaciones de las políticas públicas y la intención de voto. La casi ortogonalidad entre la evaluación de los poderes ejecutivos y la intención de voto para cargos ejecutivos, por un lado, y las evaluaciones de varias políticas públicas, por el otro, para algunos era una evidencia más de que "el brasileño no sabe votar". La evaluación de políticas públicas tendría nada o poco que ver con la intención de voto y, a través de ella, con la elección o reelección. En una investigación de Trindade y de Cew, realizada en 1976 en Caxias del Sul, la identificación partidaria era la unica variable relevante para la intención de voto puesto que las evaluaciones del costo de vida, las realizadas sobre los problemas económico-sociales, la opinión sobre los gobiernos y la ideología tenían influencia muy reducida sobre éste?.

Sin embargo, Wanderley Reis (1978) calificó esa relación en un estudio realizado en 1976, en Juiz de Fora. En ese estudio, el autor analizó la preferencia partidaria (y no la intención de voto) y concluyó que las "grandes cuestiones" político-institucionales de la época (voto directo, voto de los analfabetos, AI-5, política salarial, Lei Falcón, etc.) tenían una correlación razonable con la preferencia partidaria, sobre todo en el nivel de renta más alto (más de ocho sueldos mínimos). La observación de la Tabla IX de aquel estudio demuestra que, en niveles inferiores a ese nivel de renta, ningún coeficiente de correlación (Pbi) traspasó el 0,30. Wanderley Reis demostró, también, que las correlaciones entre lo que él llamó de "cuestiones locales" (servicio médico, escuela primaria,

6. Por orden decreciente de las correlaciones: disminuir la violencia; disminuir la corrupción; crear empleos; mejorar la atención médica y ofrecer casa propia. Aumentar el sueldo de los que ganan poco, crecimiento de la economía y disminuir la inflación no presentaban correlaciones significativas con la intención de voto por Quércia, candidato del PMDB a gobernador.

7. "Os electores paulistanos em 1986: a marca del oposicionismo", en Maria Tereza SADEK et alii. Eleições - 1986. Sao Paulo: Vértice y IDESP, 1989.

8. Esa concepción de que "o brasileiro no sabe votar" (pero la ciudadanía de los países desarrollados sí sabe...) es tan arraigada que pocos se han dado el trabajo de justificarla o de examinarla.

9. Ver, Confrontação política e decison electoral: as eleições municipais de 1976 em Caxias del Sul en REIS (org.). Op. cit. 
transporte colectivo, entre otros) y la preferencia partidaria eran más bajas (solamente una entre 32 correlaciones superaba 0,19), incluso en el nivel de renta más alto, de más de ocho sueldos mínimos). La observación de la Tabla XI de aquel estudio demuestra que el nivel de renta no se relaciona con la magnitud de las correlaciones ${ }^{10}$. La contribución de Wanderley Reis se ajusta bien con los resultados de la investigación que relatamos.

Si bien esos resultados empíricos no fueron trabajados con el objetivo de elaborar una teoría; no obstante, sin que los autores de las investigaciones lo desearan, ellos han reforzado los prejuicios de la elite y del autoritarismo, que se cansaron de afirmar que "el pueblo [brasileño] no sabe votar". Los defensores de la dictadura, añadieron una conveniente dimensión temporal: "el pueblo brasileño todavía no está preparado para la democracia (o para elegir el presidente, los gobernadores, etc.)". Sin embargo, la perplejidad que la modestia de las correlaciones ha generado ha sido ayudada por la no incorporación de algunos factores en las formulaciones teóricas y en el análisis de los datos:

- Las correlaciones de intervalo obtenidas en encuestas de actitudes, creencias y opiniones son más bajas que entre variables agregadas. Eso se demuestra con la misma base de datos, usando las mismas variables, en el nivel individual, municipal y estatal: el promedio de los coeficientes de correlación aumenta con el nivel de agregación.

- Las interrelaciones entre las varias evaluaciones son, también, modestas. Por tanto, ninguna evaluación de una política pública específica representa, adecuadamente, el conjunto de las evaluaciones.

- Empíricamente, con frecuencia, los índices tienen un poder de predicción substancialmente mayor del que gozan los indicadores, en el caso representados por las evaluaciones de políticas públicas individualizadas.

- Cuando la elección incluye un partido/ejecutivo que gobierna o ha gobernado, y otro que no lo hizo, la comparación es entre un conjunto de observables y otro, de no-observables.

Aprovechando la circunstancia de que los dos principales precandidatos a gobernador $^{11}$ (definidos por las intenciones de voto en el momento de la investigación) eran un exgobernador, Joaquim Roriz, y el gobernador en el cargo, Cristovam Buarque, ha sido posible hacer una evaluación comparativa de políticas públicas entre dos conjuntos de observables: las políticas de Cristovam y las de Roriz.

10. Ver, Classe social e opção partidária: as eleições de 1976 em Juiz de Fora. En Fábio WANDERLEY REIS (org.), Os Partidose o Regime. Sao Paulo: Símbolo, 1978.

11. En el momento de la investigación, había precandidatos y no candidatos. De los cuatro precandidatos, uno, Augusto Carvalho, desistió a la postulación posteriormente; Cristovam obtuvo $3 \%$ más de votos que Roriz en la primera vuelta, pero fue derrotado en la segunda instancia. 


\section{CUESTIONES DE MÉTODO}

\section{Los datos}

Éste es un análisis de datos secundarios que han sido recolectados por NUPESQ de la CODEPLAN, a fines de 1997 e inicio de 1998, a través de una muestra domiciliar aleatoria estratificada por región administrativa y por nivel de consumo de energía, con base a la lista de consumidores ${ }^{12}$. Los datos han sido analizados usando las ponderaciones de la muestra. Ha sido entrevistada solamente la población que declaró tener título de elector registrado en el Distrito Federal ${ }^{13}$ y para los análisis han sido utilizadas 5.239 entrevistas.

\section{La construcción de escalas}

Todos los ítems han sido formulados de acuerdo con el siguiente formato:

¿Cuál es el Gobernador que más ha hecho (por la Seguridad Pública, entre otros) en el Distrito Federal?

\section{Cristovam Buarque.}

2. Joaquim Roriz.

3. Ningún de ellos.

4. No sabe.

5. Sin respuesta.

Uno de los ítems -¿En qué Gobierno hubo más corrupción?- no ha incluido la opción de ninguno de ellos. El coeficiente de saturación más bajo de ese ítem en el factor general puede indicar que una parcela significativa de la población tendría otro gobernador en mente.

Hipotetizé que varias políticas públicas proporcionarían un mapa substancialmente más adecuado de las evaluaciones comparativas del desempeño de los gobernadores en relación a las políticas públicas, que apenas una o dos. He usado, entonces, dos tipos consagrados de escalas: escalas sumatorias y puntuaciones factoriales. He recodificado las evaluaciones, buscando la ordinalidad de las respuestas, basándome en la polarización entre Cristovam Buarque y Roriz, usando los valores 1-Cristovam Buarque; 2Otras respuestas y 3-Roriz. La ordinalidad, no obstante, es discutible: ella se basa en la polarización entre Cristovam Buarque y Roriz, una observación sostenida por el hecho de que pocos entre los que pretendían votar por uno de los dos ex gobernadores votarían

12. La lista de la Companhia de Eletricidade de Brasilia es la más satisfactoria porque la mayoría de la población está vinculada al sistema.

13. Una precaución necesaria dada la alta tasa de migraciones hacia Brasilia y la activa frontera con Goiás y Minas Gerais, muchos electores registrados en eses estados intentaran votar en el Distrito Federal. 
por el otro, en el caso de que el candidato preferido no alcanzara la segunda vuelta, sea privilegiando a Arruda, sea anulando el voto, votando en blanco, o absteniéndose, mientras que los que preferían a Arruda se dividían entre los dos principales opositores ${ }^{14}$.

En el índice sumatorio he agregado los valores correspondientes a las diez evaluaciones, adjudicando un peso igual a todas. El índice variaba desde 10 (el valor más alto pro-Cristovam y más bajo pro-Roriz) a 30 (más bajo valor pro-Cristovam y más alto pro-Roriz). Reduje el número de categorías, a partir de las frecuencias marginales, juntando categorías adyacentes con baja frecuencia y con base en el poder de diferenciación. De este modo, las categorías adyacentes con distribuciones semejantes de la intención de voto han sido agrupadas. He agregado las dos primeras (las pro-Cristovam), las dos siguientes y las cinco últimas (las pro-Roriz), renumerándolas de 1 a 14 . Para verificar si esas evaluaciones se estructuran con otras dimensiones de la psicología política del elector brasiliense, he correlacionado el puntaje en ese Índice Sumatorio de Evaluación Comparada del Desempeño de los Gobernadores con otras variables, tomadas como dependientes.

En el análisis factorial, he usado la solución de los componentes principales, sin rotación, autovalor (eigenvalue) de 1 como límite para la extracción de un factor. Hubo, como se esperaba, un fuerte factor general, en el cual todas las evaluaciones tienen coeficientes de saturación satisfactorios, variando de $-0,45$ (corrupción, la única formulada negativamente) a 0,707 , Seguridad, a lo largo del eje Cristovam-Roriz y otro factor claramente secundario (su autovalor, de 1,334, contrasta con el del primer componente de

TABLA I. Comunalidades de las evaluaciones de políticas públicas específicas

\begin{tabular}{l|c|c}
\hline \multicolumn{1}{c|}{ VARIABLES } & Inicial & Extracción \\
\hline CORRUPCIÓN* & 1,000 &, 202 \\
\hline EDUCACIÓN & 1,000 &, 597 \\
\hline SEGURIDAD & 1,000 &, 558 \\
\hline TRÁNSITO & 1,000 &, 707 \\
\hline TRANSPORTES & 1,000 &, 557 \\
\hline HABITACIÓN & 1,000 &, 564 \\
\hline SANEAMIENTO URBANO & 1,000 &, 482 \\
\hline HA HECHO MÁS POR EL METRO & 1,000 &, 437 \\
\hline PRÓXIMO DEL PUEBLO** & 1,000 &, 535 \\
\hline AYUDA LOS EMPLEADOS PÚBLICOS & 1,000 &, 451 \\
\hline HA GENERADO EMPLEOS & 1,000 &, 516 \\
\hline
\end{tabular}

* Esa evaluación obedecía a un formato diferente, el que confirma que la forma de preguntas o ítems afecta las correlaciones entre ellas.

** Ese ítem no se refería a una política pública sino a una imagen pública. Respondía a la percepción de Roriz como "próximo al pueblo" y de Cristovam Buarque como un intelectual "distante del pueblo".

(Método de Extracción: Componentes Principales)

Fuente: Elaboración propia.

14. La necesidad de esa explicación se debe a las juiciosas críticas metodológicas de Yuri Suárez Dillon Soares a una versión preliminar del trabajo. 
4,271). En esa dimensión, el coeficiente de saturación más elevado corresponde a la evaluación de las políticas relativas al tránsito.

La comunalidad de las evaluaciones de las políticas específicas es muy variable. La corrupción, quizás por tener un formato diferente (la única que no tiene un formato de Likert modificado), ha presentado, como se esperaba, una comunalidad más baja. Excluyendo la corrupción, las comunalidades varían de 0,44 al 0,71, aproximadamente. Eso nos informa cuál es el porcentaje de la varianza de cada ítem que está en la matriz, y qué porcentaje está fuera de ella. Aproximadamente, la mitad de la varianza de las evaluaciones específicas puede ser explicada con los dos factores.

TABLA II. Porcentaje de la varianza total explicada por cada componente

\begin{tabular}{c|c|c|c}
\hline & $\begin{array}{c}\text { Autovalores } \\
\text { (eigenvalues) Iniciales }\end{array}$ & & \\
\hline Componente & Total & \% de la varianza & $\%$ acumulada \\
\hline 3 &, 873 & 7,940 & 58,895 \\
\hline 4 &, 793 & 7,212 & 66,107 \\
\hline 5 &, 629 & 5,715 & 71,822 \\
\hline 6 &, 608 & 5,523 & 77,346 \\
\hline 7 &, 571 & 5,191 & 82,537 \\
\hline 8 &, 546 & 4,964 & 87,501 \\
\hline 9 &, 483 & 4,393 & 91,893 \\
\hline 10 &, 460 & 4,178 & 96,072 \\
\hline 11 &, 432 & 3,928 & 100,000 \\
\hline
\end{tabular}

Método de Extracción: Componentes Principales

El área ceniza marca los componentes aceptados por el criterio del autovalor (eigenvalue).

Fuente: Elaboración propia.

El análisis de la matriz de los componentes nos demuestra que el primer factor es claramente un Factor General de Evaluación, en el cual pesan todas las políticas. Seguridad Pública es la que tiene más alto coeficiente de saturación pero varias políticas están entre 0,6 y 0,7. El Factor 2 enfrenta a las políticas de Tránsito -quizás el gran éxito de la Administración Cristovam- con las de Habitación -quizás el gran éxito de la Administración Roriz- a través de la política de distribución de lotes.

TABLA III. Matriz de los componentes principales

\begin{tabular}{l|c|c}
\hline & 1 & \multicolumn{2}{|c}{ Componentes } \\
\hline Corrupción &,- 450 & $-6.337 \bar{E}-03$ \\
\hline Educación &, 627 &,- 452 \\
\hline Seguridad &, 707 &,- 241 \\
\hline Transito &, 540 &,- 644 \\
\hline Transportes &, 688 &,- 290 \\
\hline Habitación &, 564 &, 496 \\
\hline Saneamiento urbano &, 693 & $3.167 \mathrm{E}-02$ \\
\hline Metro &, 562 &, 347 \\
\hline Amigo del Pueblo &, 659 &, 317 \\
\hline Empleados públicos &, 619 &, 262 \\
\hline Empleo y renta &, 693 &, 188 \\
\hline
\end{tabular}

Extracción por el Método de los Componentes Principales.

a Han sido obtenidos dos (2) componentes.

Fuente: Elaboración propia. 
En lo que concierne a la variable dependiente, la intención de voto, cuya ordinalidad también es discutible, en algunos análisis he recodificado los datos, incluyendo solamente las preferencias por Cristovam y otras respuestas, Roriz y otras respuestas, etc. Las respuestas dicotómicas han sido analizadas usando una regresión logística binominal; mientras aquellas que cuentan con más de dos respuestas categóricas han sido analizadas con una regresión logística multinomial ${ }^{15}$.

\section{EL “ENIGMA" DE LA APROBACIÓN SUPERIOR A LA INTENCIÓN DE VOTO}

Uno de los frecuentes "enigmas" generados por las investigaciones electorales es la disparidad entre la alta aprobación de algunos gobiernos (más alta), por un lado, y la intención de voto moderada por su reelección (más baja), por otro ${ }^{16}$. En Brasilia, consistentemente, en investigaciones diferentes realizadas por varias agencias, el porcentaje que aprobaba el Gobierno de Cristovam Buarque era más alto que el de los que pretendían votar en él. Igual pasaba en otros estados, como Minas Gerais. En el Distrito Federal, la diferencia llegó, en algunas investigaciones, a más de 30 puntos porcentuales. El "enigma" no tiene razón de ser: la aprobación/desaprobación de un Gobierno no compara dos más candidatos. Es una "calificación" dada de acuerdo con criterios internos de cada uno. En el caso de Cristovam Buarque, la calificación era alta. Sin embargo, la intención de voto refleja una selección entre candidatos. En una hipotética selección entre cuatro ex gobernadores, todos podrían tener buenas evaluaciones (ojalá fuese siempre igual en Brasil). Sin embargo, solamente uno podría ser el elegido. El primer instrumento mide si la población piensa que el gobernador es bueno; el segundo mide si ella piensa que es el mejor candidato, lo que conlleva una comparación con otros.

\section{EL MITO DE LA IRRACIONALIDAD}

Esas falsas inconsistencias han llevado a algunos analistas a aplicar, al Distrito Federal y a otros estados, más de una vez, la vieja y errónea acusación de que "el brasileño no sabe votar". Esa acusación, de tanto repetida, se transformó en mito y

15. Sin embargo, en las multinominales, la distribución es muy despareja, lo que afecta la confiabilidad en los resultados.

16. Además de servir de guías electorales, el conocimiento de las evaluaciones del desempeño de los gobernadores -el actual o pasados-es un instrumento de gobierno. Ellas revelan cuáles son las áreas comparativamente fuertes y cuáles las áreas comparativamente débiles, de acuerdo con la opinión pública. Las creencias, evaluaciones sectoriales de desempeño; la percepción de áreas de mayor necesidad, son más estables que la intención de voto y revelan necesidades y prioridades de la población. Debemos distinguir entre democracia electoral y democracia en el gobierno (democracy in govenance). Ser elegido democráticamente es una cosa, gobernar democráticamente es otra. Usar surveys (encuestas) para impedir que se abra un hueco entre el Gobiemo y la población es una práctica común en los países centrales. 
un segmento importante de la propia población pasó a sostenerla. Así, diferentes encuestas, realizadas con años de diferencia entre sí, demuestran que parte sustancial de la población está de acuerdo con la afirmación de que "el pueblo no sabe votar". Lucía Avelar, analizando datos relativos a 1982, controlando por edad, nivel educativo y sexo (subdividiendo las mujeres en profesionales y amas de casa), ha concluido que, en ocho áreas metropolitanas, los que acreditaban que "el pueblo no sabe votar" representaban entre uno y dos tercios de la población, dependiendo del subgrupo (Avelar, 1989). Ese hallazgo no es una peculiaridad local, ni de género: un 56,5\% de los estudiantes del Río Grande del Norte se manifestaron contrarios a darle la posibilidad de votar a los analfabetos ${ }^{17}$.

Moisés informó que en 1972 y en 1982, solamente el 50\% y el $47 \%$ de los encuestados concordaban con la afirmación de que "el pueblo sabe votar". En lo que concierne al voto de los analfabetos, en 1972, un "año de plomo" ${ }^{18}$, solamente el $38 \%$ de los entrevistados se manifestaba a favor del mismo mientras que en 1982, con la distensão y los cambios en la estructura partidista, cerca del $60 \%$ favorecía el voto de los analfabetos. En este sentido, se advierte la influencia de la represión y del régimen político-partidario sobre este tipo de orientaciones ciudadanas. El apoyo al voto de los analfabetos se quedó, aproximadamente, en ese nivel en 1989 y 1990. Y así resulta claro el efecto de la dictadura sobre la confiabilidad de las respuestas a las encuestas de opinión y sobre las creencias democráticas, pero es imposible determinar dónde empieza una y termina la otra. En otra Tabla, Moisés (1993) proporcionó series que cubrían doce años, de 1978 al 1990, en las que el porcentaje contrario al voto de los analfabetos varía entre $31 \%$ y $44 \%$.

Una vertiente de la "teoría" de que el brasileño no sabe votar invierte la relación entre la evaluación del desempeño de las políticas públicas y la intención de voto ${ }^{19}$. De acuerdo con ella, los electores desarrollarían actitudes positivas o negativas en relación a los partidos y candidatos y, a partir de ellas, evaluarían positiva o negativamente las políticas públicas del Gobierno. Paradójicamente, eso implicaría algunos patrones opuestos a los vistos anteriormente:

- Las correlaciones entre evaluaciones de políticas públicas específicas, por un lado, y las preferencias partidarias y/o intención de voto, por el otro, serían siempre altas.

- Las frecuencias marginales de las diversas evaluaciones serían semejantes, tendrían poca variancia entre sí ya que quien apoyase a un partido o candidato, apoyaría también todas, o casi todas, las políticas públicas ejecutadas; quien rechazase al partido o candidato, haría lo mismo con las políticas públicas implementadas o propuestas por ellos.

17. Ver FERREIRA y VALE SOUSA (1996: 152).

18. Uno de los años más duros de la dictadura.

19. Coloco "teoría" entre comillas porque afirmaciones hechas por líderes políticos conservadores, sobre todo durante el régimen militar, y la existencia de una minoría significativa de la población que está de acuerdo, en los surveys, con esa afirmación, no bastan para configurar una teoría. 
- Las correlaciones entre las diversas evaluaciones de las políticas públicas, que serían simples reflejos de las preferencias por partido/candidato, serían, también, muy altas, formando bloques, conglomerados excepcionalmente apretados.

- Las ganancias marginales en la explicación de la varianza de la intención de voto a través de la construcción de índices compuestos, en comparación con indicadores simples, serían pequeñas, debido a que gran parte de la varianza de cada evaluación sería común a las otras evaluaciones.

Sin embargo, en todas las investigaciones encontramos variaciones significativas entre las evaluaciones. La investigación electoral de 1976 produjo resultados semejantes: Lamounier (1978), analizando los datos de Presidente Prudente, mostró una variación en el desempeño gubernamental del $75 \%$ de respuestas "muy bueno", en lo que se refería a la escuela, mientras que dio al $6 \%$ en lo que se refería al costo de la vida. En lo que concierne a los servicios municipales, la aprobación más alta variaba de $61 \%$, en lo que se refería a la escuela primaria, $55 \%$ y $54 \%$ en lo que se refiere al agua y al transporte colectivo, al $21 \%$ en lo que se refería a la conservación de las calles ${ }^{20}$. En Niterói, Olavo Brasil de Lima Jr. encontró un nivel muy más bajo de satisfacción con los servicios municipales, variando de $32 \%$ (transporte colectivo) al $8 \%$ (aguas residuales) y $9 \%$ (conservación de las calles). Comparando los mismos ítems en poblaciones diferentes, verificamos que hay mucha varianza entre ellas.

La transición de la democracia con participación restringida a la democracia con participación ampliada depende de la aceptación de que "los otros" saben votar. Sea en su versión amplia (el pueblo, los brasileños), sea en su versión limitada y enfocada (los analfabetos, los que no han ido a la escuela). El rechazo del voto universal es una posición clasista y prejuiciosa, peligrosa para la democracia. El derecho de votar ha sido negado a docenas de millones de brasileños hasta 1988, con base en un argumento vagamente iluminista, que vincula la "corrección" del voto a la educación formal. Solamente los más educados sabrían votar. Es clara la necesidad de deshacerse de ese mito.

\section{ANÁLISIS: LAS EVALUACIONES SON DIFERENCIADAS, NO SON EM BLOCO}

Este trabajo usa datos de recientes investigaciones de opinión para falsificar algunos de esos mitos y dilucidar algunos enigmas sobre la política brasileña, usando las elecciones de 1998 para gobernador del Distrito Federal como ejemplo. Es parte de una serie de investigaciones que combaten los mitos de la irracionalidad y de la imprevisibilidad del elector brasileño. Como las investigaciones mencionadas han demostrado que son pequeñas o modestas las correlaciones entre la evaluación de las políticas públicas, por un lado, y la evaluación del desempeño del gobernante, la preferencia partidaria y/o la intención de voto, por el otro, el objetivo de este artículo es ir en contra de esas presunciones.

20. Ver LAMOUNIER (1978). 
Los datos relativos al Distrito Federal demuestran que los electores también diferencian entre programas y atributos de los gobernadores, actuales y pasados. Contrariamente a la ideología elitista y vanguardista que afirma, contra un mar de datos y de evidencias, que los electores brasileños no saben votar y aceptan todo tipo de propaganda, los datos demuestran que los mismos electores dan tanto a Joaquim Roriz, como a Cristovam Buarque, altos porcentajes en algunos ítems y bajos en otros. Ellos diferencian entre una política pública y otra por lo que no evalúan "en bloque", que sería la tendencia a evaluar todas las áreas con intensidad semejante, en favor de un candidato y lo que sería una característica de electores poco selectivos, del tipo "fecho, não abro e não quero saber" ${ }^{21}$. En su gran mayoría, los electores del Distrito Federal no son de ese tipo puesto que saben diferenciar entre las políticas públicas: por ejemplo, un $66 \%$ señala que Cristovam Buarque es el gobernador que más ha hecho por la paz en el tránsito pero solamente el $11 \%$ sostiene que el es el que más ha hecho por los empleados públicos. Del otro lado, el $53 \%$ afirma que Roriz es quién más ha hecho por la habitación, en contraste con el $9 \%$ que afirma que él es el que más ha hecho por el tránsito. Hay áreas como la habitación, la educación y el tránsito en las que la gran mayoría de los electores se define por uno u otro candidato, pero en otras como el empleo y la renta, los empleados públicos y la seguridad pública, la población no parece estar satisfecha con ninguno de los dos gobernadores, abriendo espacio para otros candidatos. Los datos no ponderados nos dan las siguientes distribuciones:

Tabla IV: Los electores diferencian entre las políticas públicas de los gobernadores

\begin{tabular}{l|c|c|c}
\hline \multicolumn{1}{c|}{ Área de Política Pública } & \multicolumn{2}{|c}{ ¿Quén ha hecho más en esa área por el Distrito Federal? } \\
\hline Violencia en el Tránsito & $\begin{array}{c}\text { Joaquim Roriz } \\
9 \%\end{array}$ & $\begin{array}{c}\text { Cristovam Buatque } \\
66 \%\end{array}$ & $\begin{array}{c}\text { Otras respuestas } \\
25 \%\end{array}$ \\
\hline Educación & $25 \%$ & $49 \%$ & $34 \%$ \\
\hline Transporte público & $17 \%$ & $33 \%$ & $50 \%$ \\
\hline Saneamiento básico y urbanización & $25 \%$ & $31 \%$ & $44 \%$ \\
\hline Seguridad pública & $20 \%$ & $30 \%$ & $50 \%$ \\
\hline Metro & $44 \%$ & $18 \%$ & $38 \%$ \\
\hline Empleo y renta & $20 \%$ & $14 \%$ & $66 \%$ \\
\hline Habitación & $53 \%$ & $13 \%$ & $34 \%$ \\
\hline Empleados públicos & $22 \%$ & $11 \%$ & $67 \%$ \\
\hline
\end{tabular}

Fuente: Elaboración propia.

Los datos de la investigación en el Distrito Federal sugieren que los electores analizan y evalúan candidatos (en el momento de la investigación, eran pre-candidatos, todavía no oficialmente lanzados) a partir de una plataforma diversificada ${ }^{22}$. Asimismo, muchos partidarios de Cristovam parecían creer que las elecciones estaban ganadas debido al éxito de sus políticas en el tránsito y en la educación. Han percibido que dos de los

21. "Voto por él, no cambiaré mi voto y no quiero hablar de eso".

22. La "intuición", basada en el iluminismo, sugiere que la complejidad de la plataforma crecería con el nivel educacional. Los datos no apoyan esa posición. 
ítems de mayor éxito en las comparaciones del desempeño gubernamental que favorecían a Cristovam eran el tránsito y la educación. La población ha respondido bien a esa campaña y al papel del GDP (Gobierno Democrático y Popular): 66\% de los entrevistados afirmaban que el desempeño de Cristovam ha sido superior al de Roriz, $25 \%$ sostenían que ninguno de los dos ha sido el mejor o dieron otras respuestas, y solamente $9 \%$ indicó que el de Roriz ha sido superior. Por ejemplo, la bolsa-escuela es hoy uno de los programas más populares del GDP, siendo merecedor de elogios internacionales. A partir de esos datos, y solamente de esos datos, el lector desprevenido podría concluir que la intención de voto favorecería a Cristovam. ¡Equivocado! Aun cuando cada administración realice sus propios énfasis, han sido pocos los casos en que una única política pública garantice una reelección. La política de tránsito es una de las dimensiones en las que la intención de voto está anclada. La educación es solamente otra. Hay muchas más. Asimismo, $46 \%$ de los que respondieron que Cristovam ha sido el gobernador que más ha hecho para disminuir la violencia en el tránsito no votaría por él: $29 \%$ votarían por Roriz, $13 \%$ por Arruda y $4 \%$ por Augusto Carvalho ${ }^{23}$. Una política pública acertada puede ayudar mucho a la valoración de los ciudadanos pero raramente define el resultado de una elección.

Lo mismo se aplica a Roriz o a cualquiera de los otros gobernadores. Roriz es popular debido a la distribución de lotes y a su imagen de "próximo al pueblo". ¿Significa eso que tendría la victoria garantizada en las elecciones en el caso de que el contexto preelectoral se mantuviese? No. Objetivamente, Roriz distribuyó más lotes que cualquier gobernador. Eso le granjeó el apoyo entre los que recibieron los lotes y entre sus familiares y amigos. Provocó, quizá, simpatías entre los que aspiraban recibir un lote. Inicialmente, la política de distribución de lotes era el sueño de cualquier político: ubicó en asentamientos distantes a los "invasores" ${ }^{24}$, considerados incómodos y/o peligrosos por los residentes de áreas de clase alta, media o trabajadora establecida, y los transfirió para áreas distantes, dándoles lotes. Con ello, agradó a todos. Posteriormente, esa política pasó a ser cuestionada porque la criminalidad comenzó a ser una característica de esas áreas y porque la tasa de crecimiento demográfico de varios de esos asentamientos fue muy alta. Setenta y cuatro por ciento de los entrevistados estaban de acuerdo con que la distribución de lotes hecha por Roriz atrajo inmigrantes. Electoralmente, Roriz arrasó entre la minoría que señalaba que los asentamientos no atraerían migrantes internos: $60 \%$, en claro contraste con el $31 \%$ entre los que acreditaban que atraerían. Los demás precandidatos crecerán entre los que acreditaban que la distribución de lotes atraía inmigrantes: Cristovam del $11 \%$ al $24 \%$; Arruda del $6 \%$ al $14 \%$ y Augusto Carvalho del $1 \%$ al $4 \%$. Éste se convirtió en uno de los principales temas electorales. La opinión pública sobre la creación de nuevos asentamientos se modificó: la población, que era avallasadoramente favorable pocos años antes, cambiaría en la época de la

23. En contraste, tres de cada cuatro $(76 \%)$ de la minoría que hallaba que Roriz había sido quien más disminuyó la violencia en el tránsito votarían por él, $7 \%$ por Arruda y $5 \%$ por Cristovam.

24. La denominación quizá sea políticamente incorrecta: la preferida por algunos estudiosos y activistas es "ocupante". 
recolección de datos. La creación de nuevos asentamientos era sostenida por sólo el $42 \%$. Entre los que apoyaban la creación de nuevos asentamientos, Roriz recibía el $45 \%$ de las preferencias; entre los que no apoyaban, el porcentaje caía al $23 \%$. Los demás precandidatos, al contrario, subían: Cristovam de $19 \%$ para $27 \%$; Arruda de $9 \%$ para $16 \%$ y Augusto Carvalho de $2 \%$ para $5 \%$. La política de distribución de lotes ha sido uno de los temas centrales de la campaña electoral, debido a la razonable correlación con la intención de voto.

\section{Gráfico I}

La influencia de la creencia en que los asentamientos han estimulado más migrantes internos sobre la intención de voto en el Districto Federal

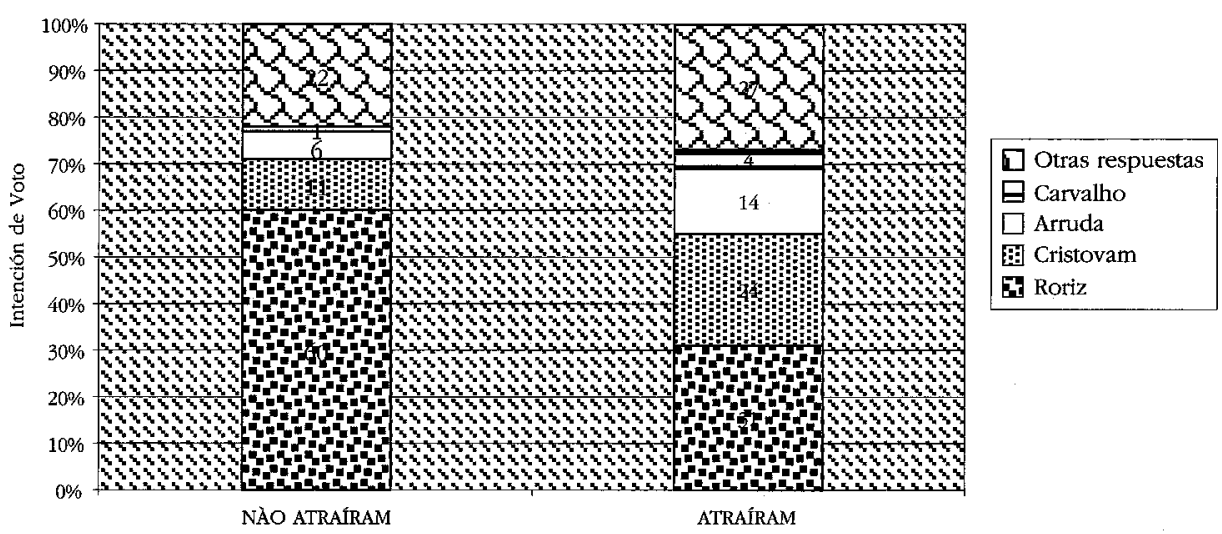

La tercera columna de la Tabla IV se refiere al porcentaje de los que acreditaban que quien más ha hecho en aquella área no ha sido Cristovam Buarque, ni Roriz. El porcentaje no es uniforme, variando de $25 \%$ en la política de tránsito al $66 \%$ y $67 \%$ (de dos en tres) en lo que concierne a la generación de empleo y renta y apoyo a los empleados públicos. Esa variación implica que la población distribuye las políticas públicas en tres categorías: aquellas en que el desempeño de Cristovam ha sido mejor; aquellas en las que el desempeño de Roriz ha sido mejor y aquellas en las que el mejor desempeño no ha sido ni de uno ni de otro, pero sí de alguno de los demás gobernadores del Distrito Federal.

Sin embargo, esa investigación reveló algunos males: la población brasiliense tiene un alto grado de coherencia entre la evaluación de las políticas públicas y la intención de voto, contrariando los descubrimientos de las investigaciones pioneras en esta área. Cuando usamos acumulativamente las evaluaciones comparadas en diez sectores de actividad gubernamental, la relación es muy estrecha. Empecemos por la relación entre el Índice Sumatorio de Evaluación Comparada del Desempeño en Políticas Públicas y la intención de voto para los cuatro precandidatos. El Gráfico II demuestra que la evaluación acumulada de las políticas públicas tiene una relación clara y definida con la intención de voto. 
Gráfico II

Evaluaciones de las políticas públicas (índice sumatorio)

e intención de voto para gobernador

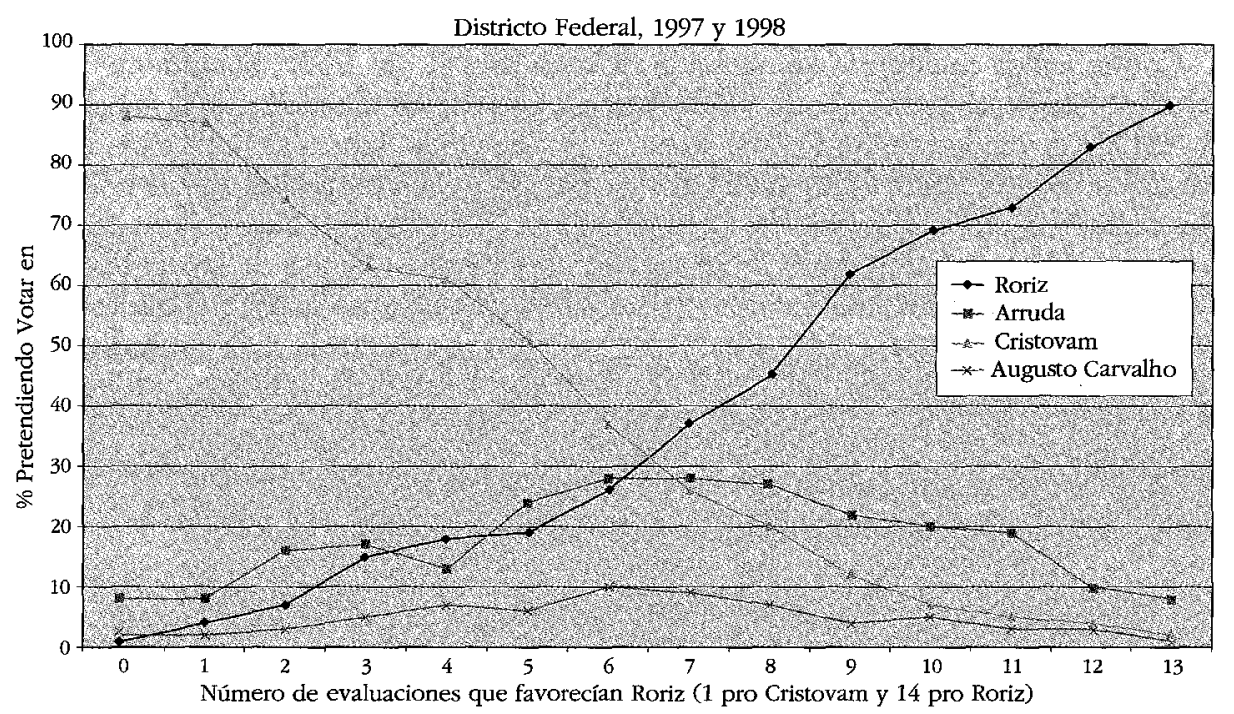

El Gráfico II nos demuestra que las distribuciones no son aleatorias. Hay clara tendencia decresciente en la intención de voto para Cristovam Buarque a cada aumento en el Índice sumatorio y una clara tendencia cresciente en la intención de voto para Roriz. Si la "teoría" de que los brasileños votan basados en personales de carácter irracional fuera válida, o si los electores responderán solamente al carisma del candidato ${ }^{26}$, de forma irracional, sin base evaluativa, si no relacionaran las políticas públicas al voto, no habría asociación entre las evaluaciones y la intención de voto. Asimismo, si los electores respondiesen solamente a señales emocionales del candidato preferido, casi todos evaluarían mejor las políticas públicas implementadas por "su" candidato.

Las intenciones de voto para Arruda y Augusto Carvalho obedecían a una ecuación curvilinear, como sería de esperar cuando aceptamos que las "otras respuestas" (ni Cristovam Buarque, ni Roriz) indicarían mayor disponibilidad para aceptar terceros candidatos. Quizás algunos argumenten que eso es "intuitivo" a partir del momento en que se acepte que hay una relación entre evaluaciones de las políticas públicas e intención de voto. Quién no aceptar esa relación, para ser consistente,

25. Coloco, otra vez, la "teoría" entre colmillas porque es más una postura que una teoría coherente elaborada. Quienes la proponen tampoco se preocupan de testarla o falsarla, limitándose a afirmarla.

26. Erróneamente visto como un atributo personal del candidato y no como una relación entre esos atributos y sectores del electorado.

27. Quién sabe qué significa eso. 
deberá defender una distribución aleatoria de las preferencias en cada intervalo de la escala, reproduciendo la distribución total de frecuencias de las intenciones de voto. No es posible defender que el voto responde al "carisma" del candidato, sin relación con las características de los electores y sus intereses ${ }^{28}$.

Continuemos analizando la intención de voto para Roriz. El $\mathrm{R}^{2}$, basándome en el coeficiente de Pearson lineares de $0,97^{29}$. Tanto la inspección visual cuanto la magnitud del coeficiente de determinación no dejan duda sobre cuán íntima es la relación entre el Índice de Desempeño y la intención de voto para Roriz. La intimidad de esta relación no es captada en su totalidad por ítems (evaluaciones) individualizados que, aun cuando correlacionados con la intención de voto, presentan amplios errores de especificación. Ése es un punto importante: los que relacionaron evaluaciones individualizadas, por un lado, y intención de voto o preferencia partidaria, por el otro, han encontrado relaciones fracas o modestas. Pero la evaluación del desempeño de las políticas públicas de un Gobierno es multidimensional. Las relaciones simples, bivariadas, tomando un servicio público de cada vez, dejan fuera las demás dimensiones del desempeño de un gobernante y, consecuentemente, presentan un error de especificación mayor.

\section{Gráfico III}

Evaluación de las políticas públicas e intención de voto para Cristovam Buarque Soluciones Linear y Polinomio de Tercer Grado

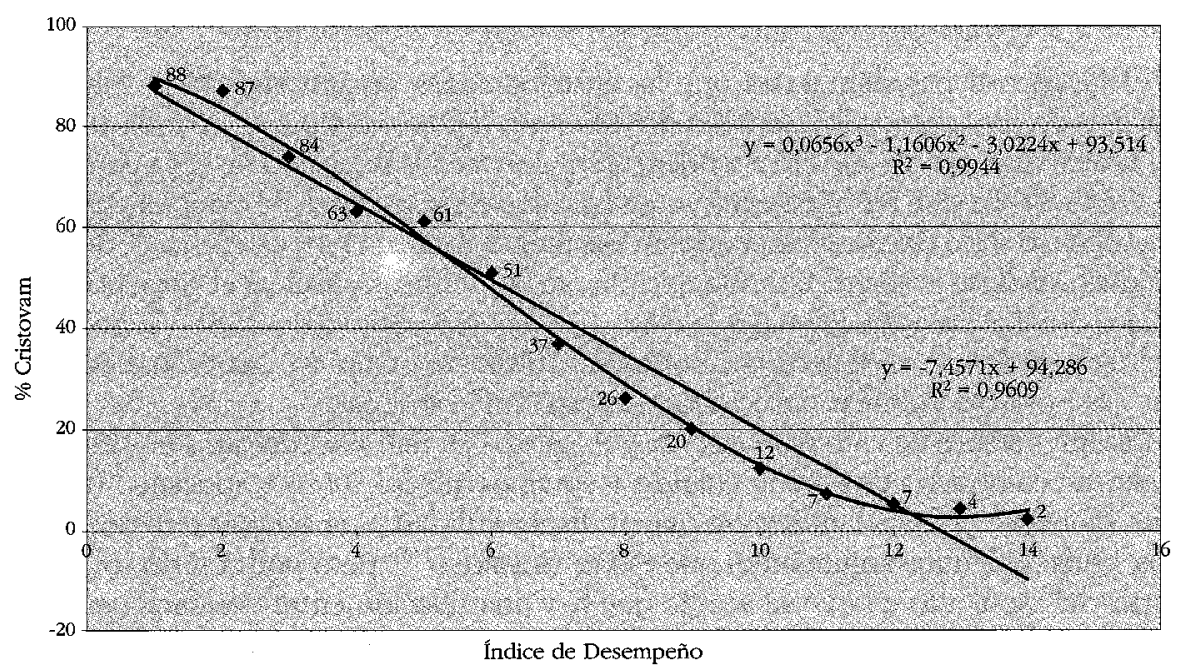

28. Obviamente, tal como los perciben los propios electores y no los analistas políticos y/o dirigentes partidarios.

29. Aun cuando la inspección visual de la gráfica sugiera una sinuosidad, y la solución polinomial de tercer grado nos proporcione un $\mathrm{R}^{2}$ de 0,99 , la solución linear, más simple y elegante, es preferible. Dos por ciento de pérdida en la explicación de la varianza es más que compensada por la simplificación de la teoría. 
Como sería de esperar, la relación entre el Índice de Desempeño y la intención de voto para Cristovam Buarque es negativa, por que el Índice está hecho en la dirección de "a más alto valor, peor la evaluación de las políticas públicas de Cristovam". La solución polinomial proporciona valores muy altos, pero la linear es satisfactoria ${ }^{30}$.

La relación entre la evaluación comparada del desempeño de los gobernadores y la intención de voto parece intuitiva: se espera que quien evalue mejor el desempeño de un gobernador en varias políticas públicas esté dispuesto a votar en él. En tanto, en la actual encuesta, esa relación es muchísimo más intensa que en investigaciones anteriores. Las gráficas demuestran que tanto el porcentaje, sobre el total de las intenciones de voto, de los que prefieren Cristovam o Roriz, puede ser explicada satisfactoriamente por una solución linear basada en los 14 valores de evaluación del desempeño ${ }^{31}$.

La relación entre el valor en el Índice Sumatorio que representa el eje CristovamRoriz y la intención de voto por Arruda y Augusto Carvalho (cuyas políticas públicas -como diferente de sus propuestas para ellas- no han sido evaluadas, porque ellos no han sido gobernadores) es claramente curvilinear, siendo bien descritas por un polinomio de segundo grado. El coeficiente de determinación $\left(R^{2}\right)$ es de 0,82 con Arruda y 0,77 con Carvalho. La curvilinearidad era esperada: las evaluaciones consistentemente positivas de Cristovam Buarque se concentran en uno de los extremos de la escala y las de Roriz, en el otro. Aritméticamente, quien creía que $n i$ Cristovam ni Roriz había sido quien más hiciera por tal o cual política pública, se concentró en el medio de la distribución del índice. En los valores 7, 8 y 9 (la escala varía de 1 a 14) Arruda recibió más del $25 \%$ de las preferencias y Augusto Carvalho obtenía más de $8 \%$ en los niveles 7 y 8 . Arriba y abajo de esos límites, los porcentajes prefiriendo esos dos candidatos disminuían.

La conclusión es que, en el Distrito Federal, la intención de voto por un ex gobernante es función de la evaluación de un coyunto de políticas públicas. Si los determinantes "últimos" son otros, ellos pasan por las evaluaciones de las políticas públicas.

Sin embargo, ese resultado es la excepción en la historia de las investigaciones electorales brasileñas. Von Mettenheim (1995), analizando datos de investigación de 1982 en el Sudeste y en el Noreste, ha probado que la posición en una escala de actitudes en relación a los temas nacionales influenciaba considerablemente la intención de voto para gobernador (Beta de 0,39, añadiendo 0,15 al $\mathrm{R}^{2}$ ). Sin embargo, usando una escala semejante sobre temas locales (más semejantes a los temas investigados en el Distrito Federal) se incrementaba muy poco (Beta de 0,06 y ninguna mejoría en el $\mathrm{R}^{2}$ ). Los resultados llevaron a Von Mettenheim (1995: 164) a afirmar que "views on the local issues in the urban samples in the southeast and northeast remain unrelated to voter choice".

30. Con varias o muchas observaciones, difícilmente las soluciones polinomiales no proporcionarán coeficientes de determinación más elevados que las lineares. Eso no justifica su uso indiscriminado, que podríamos llamar de "jugar de polinomio", peligro real para los que se concentran exclusivamente en la varianza explicada. La diferencia entre las varianzas explicadas tiene que ser, ella propia, estadísticamente significativa y el investigador debe justificar teóricamente la opción polinomial.

31. Aquí también se gana poco con las soluciones polinomales lo que sugiere adoptar la solución linear, más simple y elegante. 
Esa conclusión es la única que los datos sobre las elecciones de 1974, 1978 y 1982, permiten. Asimismo, en el que concierne la relación entre "Cuestiones o temas locales" y "evaluaciones de servicios públicos", de un lado, y preferencia partidaria y/o intención de voto, del otro, los datos de las elecciones de 1998 en el Distrito Federal revelan una situación de excepcionalidad. Este carácter excepcional se refiere a las investigaciones realizadas, y no al país, ni a su historia. Si construimos una matriz compuesta por áreas metropolitanas y años, las investigaciones anteriores cubren pocas áreas en pocos años.

\section{Análisis: situación de clase y organización de las evaluaciones}

El mito de la irracionalidad, a la vez, es circunscrito a los analfabetos y, más ampliamente, a los electores menos educados. En respuesta a la pregunta: “¿cómo funciona la organización de las creencias y evaluaciones del desempeño en la cabeza de los electores?", vemos que hay varios prejuicios de clase asociado con visiones estereotipadas en relación a los electores menos instruidos, con menos educación formal. Uno de ellos, el más común, supone que la intención de voto de los menos educados sea "menos ra cional". Este prejuicio está presente tanto en los vanguardistas de la izquierda como en los defensores del régimen militar. La elección, política y electoralmente, estaría fundamentada en factores personalistas y no en factores racionales, derivados de sus intereses.

Nuestros datos demuestran que no es así. En cada uno de cinco niveles educacionales encontramos altas correlaciones entre las evaluaciones del desempeño de los gobernadores en diferentes políticas públicas sectoriales y la intención de voto ${ }^{32}$.

Tabla V. Coeficientes de correlación gama ordinal entre evaluaciones del desempeño e intención de voto por nivel educacional. Investigación CODEPLAN, 1998.

\begin{tabular}{l|c|c|c|c|c}
\hline \multirow{2}{*}{ ÁREA TEMÁTICA } & \multicolumn{5}{c}{ NIVEL EDUCACIONAL } \\
\cline { 2 - 6 } & BAJO & MEDIO-BAJO & MEDIO & MEDIO-ALTO & ALTO \\
\hline TRÁNSITO & 0,57 & 0,62 & 0,82 & 0,68 & 0,73 \\
\hline EDUCACIÓN & 0,71 & 0,71 & 0,81 & 0,74 & 0,86 \\
\hline SANEAMIENTO & 0,70 & 0,65 & 0,86 & 0,80 & 0,70 \\
\hline PUEBLO & 0,81 & 0,85 & 0,84 & 0,82 & 0,75 \\
\hline SEGURIDAD & 0,70 & 0,70 & 0,80 & 0,80 & 0,68 \\
\hline
\end{tabular}

Fuente: Elaboración propia.

La Tabla $\mathrm{V}$ avanza nuestra compresión de la racionalidad y de la ideología de los electores del Distrito Federal, resaltando tres aspectos:

- Las evaluaciones del desempeño de los gobernadores en políticas públicas individualizadas presentan altas correlaciones con la intención de voto.

32. Han sido usados varios coeficientes, tanto nominales, cuanto ordinales. Reportamos los gama ordinales. 
- En cuatro áreas de evaluación -educación (una de las áreas en las que Cristovam Buarque presenta sus mejores resultados); seguridad y saneamiento (las áreas intermedias de evaluación) y "aproximación con el pueblo" (el área de mejor desempeño de Roriz)- las correlaciones son substanciales. Hay un coeficiente por debajo de 60; cuatro en los 60 , nueve en los 70 y once en los 80 ;

- Las correlaciones son elevadas en todos los niveles educacionales. Nosotros no encontramos corrrelaciones más altas entre evaluaciones e intención de voto en los niveles educacionales más altos.

La magnitud de esas correlaciones entierra los mitos que señalan que los brasileños no "saben votar", que afirma que no hay relaciones íntimas entre evaluaciones de políticas públicas e intención de voto, y defiende el prejuicio de que son los más instruidos lo que saben hacerlo. Sin embargo, hay datos menos "entusiasmados" con esa hipótesis que han sido recolectados por investigaciones cuidadosas realizadas durante el régimen militar. Olavo Brasil utilizó tests de $X^{2}$ que demuestran que, entre los 14 indicadores que Wanderley Reis (1978) llamó de "grandes cuestiones", el número de asociaciones significativas en el nivel de $10 \%$ era bajo, habiendo una diferencia en el electorado con alta escolarización ( $57 \%$ de las asociaciones eran significativas) y baja escolarización (30\% significativas). ¿Qué es lo que estos resultados sugieren? Una vez más indican que los resultados de la investigación en el Distrito Federal difieren del conjunto clásico de investigaciones electorales realizadas durante la dictadura, que ha generado parte substancial del conocimiento sobre procesos electorales en el Brasil.

\section{Análisis: el efecto acumulado de las variables estructurales y de las evaluaciones sobre la intención de voto}

En el Distrito Federal, como en casi todas partes, el voto también es una función de la posición social. Lo que es inusitado aquí es que los menos instruidos, que están en el fondo de la pirámide de estratificación social, apoyaron al precandidato de la derecha, mientras que los más instruidos, cuya situación de clase es media o alta, apoyaron al candidato de la izquierda. La evaluación del desempeño de las políticas públicas sectoriales y la situación de clase influenciaron la intención de voto acumulativamente: entre los que sostenían que había sido Cristovam Buarque quien había hecho más por la educación. El porcentaje de los que esperaban votar por él creció con el nivel educacional: de $42 \%$, entre los que tenían más bajo nivel; del $56 \%$ entre aquellos con nivel medio-bajo; $66 \%$ en el nivel medio; $69 \%$ en el nivel medio-alto, llegan a $88 \%$ en el nivel alto. Entre los que afirmaban que quien había hecho más por la educación no habían sido ni Cristovam ni Roriz o dieron otras respuestas, el porcentaje de los que pretendían votar por Cristovam es considerablemente más bajo, pero también creció con el nivel educacional: $18 \%, 22 \%, 27 \%, 37 \%$ y $47 \%$, respectivamente. Entre los que creían que había sido Roriz quien más había hecho por la educación en el Distrito Federal, los porcentajes dados a Cristovam eran muy bajos en los cinco niveles educacionales: $5 \%, 10 \%, 10 \%, 14 \%$ y $14 \%$. 


\section{Gráfico IV}

La influyencia cumulativa del nivel educacional y de la evaluación de una política pública específica (quien ha hecho más por la educación) sobre la intención de voto - Distrito Federal, 1998

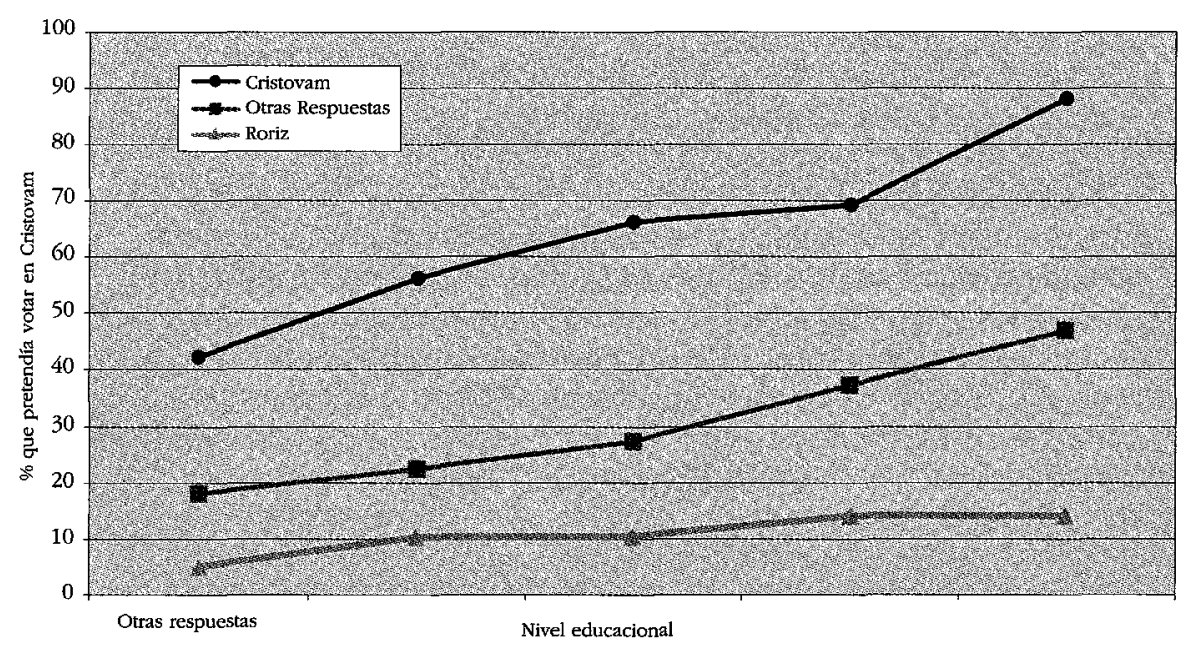

Conociendo las evaluaciones del desempeño y la educación, la previsión del voto que Cristovam obtendría varía entre el $5 \%$ (bajo nivel educacional y cree que Roriz ha hecho más por la educación) y el $88 \%$ (alto nivel educacional y cree que Cristovam ha hecho más por la educación). Resultados semejantes son obtenidos cuando sustituimos la educación por otra área en la cual la Administración de Cristovam ha tenido gran éxito, como el tránsito. En todas las asociaciones trivariadas que he investigado, las dos variables explicativas, situación de clase y evaluación de política pública, influenciaron cumulativa y significativamente sobre la intención de voto.

\section{Análisis: regresión logística binomial}

La posición metodológicamente más conservadora sugiere que una regresión logística es más compatible con las propiedades de los datos que una OLS. Las lineares podrían ser obtenidas dicotomizando las respuestas y creando una variable dependiente "dummy", sea Roriz/Otras Respuestas y Cristovam/Otras Respuestas. Iniciaremos los análisis multivariados con regresiones logísticas binomiales, usando como variables dependientes dos dicotomías: Roriz/Otras Respuestas y Cristovam/Otras Respuestas. Posteriormente, usaremos un análisis logístico multinomial. Para completar, usaremos una regresión linear, presentando los datos en el apéndice.

En la primera regresión logística binominal, he analizado la intención de voto por Roriz, tomada como variable dependiente, recodificando las respuestas como $1=$ Roriz 
y 2=Otras respuestas. El modelo ha incluido una combinación de variables "actitudinales" (las evaluaciones de las políticas públicas); socio-demográficas (educación y tiempo de residencia en el DF) y estructurales (Regiones Administrativas de residencia, agrupadas de acuerdo con su nivel socio-económico -alto, medio y bajo-) y reagrupadas de acuerdo con su historia, se iniciaran con asentamientos o no ${ }^{33}$. En una regresión "para tras", el tiempo en el DF ha sido la única variable eliminada. El modelo (sin el tiempo de residencia en el DF) arrojó un $\mathrm{X}^{2}$ de 1.419,82 que, con siete grados de libertad, es significativo en el nivel de 0,0000 . El modelo, por lo tanto, explica la intención de voto por Roriz en niveles muy exigentes de significación. El modelo permite ubicar correctamente $79 \%$ de las respuestas categóricas, $63 \%$ de los que preferían a Roriz y $88 \%$ de las otras respuestas. Evidentemente, es satisfactorio. La combinación de variables actitudinales, socio-demográficas y estructurales ha demostrado ser útil. El pseudo- $\mathrm{R}^{2}$, de Nagelkerke, de 0,47 es satisfactorio.

Tabla VI. Puntuaciones factoriales de evaluación de políticas públicas, variables socio-demográficas personales y variables estructurales sobre la categorización de intención de voto.

Clasificación para RORIZ - Valor del corte es 0,50

\begin{tabular}{l|c|c|c|c}
\hline & & \multicolumn{2}{|c|}{ Previsión } & Porcentaje \\
\hline & & 1,00 & 2,00 & Correcto \\
\hline Observados & 1,00 & 1060 & 661 & $62 \%$ \\
\hline & 2,00 & 337 & 3181 & $90 \%$ \\
\hline
\end{tabular}

Total Correcto $=81 \%$

Fuente: Elaboración propia.

Comportamiento de las variables en la equación

\begin{tabular}{|l|c|c|c|c|c|c|c|}
\hline Variable & $\mathrm{B}$ & $\mathrm{S} . \mathrm{E}$. & Wald & $\mathrm{g}$ & $\mathrm{Sig}$ & $\mathrm{R}$ & $\operatorname{Exp}(\mathrm{B})$ \\
\hline REGION ADMIN &,- 1174 &, 0307 & $\mathbf{1 4 , 6 3 2 3}$ & 1 &, 0001 &,- 0436 &, 8892 \\
\hline FACTOR 2 &,- 4764 &, 0381 & 156,5993 & 1 &, 0000 &,- 1527 &, 6210 \\
\hline FACTOR 1 & $-1,6440$ &, 0530 & 962,6050 & 1 &, 0000 &,- 3805 &, 1932 \\
\hline ESTUDIÓ &,- 1082 &, 0200 & 29,1918 & 1 &, 0000 &,- 0640 & 1,1143 \\
\hline NUEVOS ASENT. &,- 3224 &, 0418 & 59,4105 & 1 &, 0000 &,- 0930 & 1,3805 \\
\hline TIEMPO en el DF &,- 1486 &, 0245 & 36,6572 & 1 &, 0000 &,- 0723 &, 8619 \\
\hline Constante &,- 9396 &, 1614 & 33,8718 & 1 &, 0000 & & \\
\hline
\end{tabular}

Fuente: Elaboración propia.

Sin embargo, esa respuesta global no indica cuál o cuáles de las variables en la ecuación contribuyen de forma estadísticamente significativa. Observando la estadística de Wald y su significación, vemos que:

1. Todas son estadísticamente significativas en el nivel de 0,0001 (o mejor).

2. Las puntuaciones factoriales relativas a las evaluaciones de las políticas públicas tienen, como en la regresión linear, más peso que las variables estructurales.

33. La inserción de datos estructurales como atributos individuales introduce un bias en las estimativas porque da al individuo un valor promedio que puede no ser el suyo. El efecto esperado de esa inadecuación es viciar las estimativas, aumentando el error. 


\section{Análisis: regresión logística multinomial}

La utilización del análisis logístico multinomial revela el poder del modelo explicativo, así como sus límites. En el total, un $57 \%$ de los casos han sido correctamente clasificados lo que, como se podría esperar, representa una clara pérdida en relación a los modelos binomiales. Las alternativas más difíciles de clasificar son, usualmente, las de frecuencia más baja. Es una limitación de las multinominales. Existe una relación entre número de observaciones y ser correctamente clasificado. Las "otras respuestas", que a veces pueden ser consideradas como indicadores de apatía, desinterés, falta de información políticas, en aquel momento -varios meses antes de las elecciones- eran más frecuentes que las preferencias por Cristovam quien, no obstante, recibió más clasificaciones correctas; Arruda tenía la mitad de las preferencias de Cristovam y ha sido muy difícil de clasificar.

La intención de votar a Roriz ha sido satisfactoriamente explicada por el modelo: el $75 \%$ de las opciones han sido correctamente clasificadas, porcentaje que crece en un $81 \%$ cuando usamos un modelo binomial y excluimos los desinteresados, apáticos, entre otros. Dos entre cada tres (68\%) preferencias por Cristovam han sido correctamente previstas y $59 \%$ de las "otras respuestas" también lo han sido. El modelo es significativo en un nivel muy exigente. Sin embargo, las variables que explican una alternativa no tienen el mismo peso en la explicación de las demás alternativas.

Las variables que más explican la preferencia por Roriz, de acuerdo con la estadística de Wald, serían el Factor General de Evaluación de las Políticas Públicas; el Factor 2; el nivel educacional del entrevistado y residir o no en una RA que era un asentamiento nuevo (o contenía un asentamiento nuevo). Ya en lo que concierne a Cristovam, el Factor General de Evaluación de las Políticas Públicas es, prácticamente, el único que cuenta. El nivel socio-económico de la RA y la existencia, dentro de ella, de nuevos asentamientos, no son significativos en la clasificación de las preferencias por Cristovam. Los principales determinantes de las preferencias por Arruda han sido el Factor 2 y el nivel educacional. El Factor General de Evaluaciones y el tiempo de residencia en el DF son irrelevantes. Las preferencias por Augusto Carvalho eran explicadas por el nivel educacional, principalmente. El análisis binomial de las "otras respuestas" subraya la importancia de los nuevos asentamientos y, secundariamente, del Factor 2. Todas las demás variables han sido irrelevantes.

Tabla VII. Resultados del análisis logístico multinomial

\begin{tabular}{l|c|c|c|c|c|c}
\hline Clasificación & \multicolumn{7}{l}{} \\
\hline \multicolumn{7}{|l|}{ Previsión } \\
\hline Observado & Roriz & Arruda & Cristovam & Carvalho & Otras respuestas & $\%$ Correcto \\
\hline Roriz & 1.106 & 1 & 84 & 0 & 280 & $75,2 \%$ \\
\hline Arruda & 177 & 4 & 130 & 0 & 236 & $0,7 \%$ \\
\hline Cristovam & 80 & 4 & 678 & 0 & 238 & $67,8 \%$ \\
\hline Carvalho & 21 & 5 & 37 & 0 & 84 & $0,0 \%$ \\
\hline Otras respuestas & 328 & 9 & 200 & 0 & 771 & $58,9 \%$ \\
\hline Total & $38,3 \%$ & $0,5 \%$ & $25,2 \%$ & $0,0 \%$ & $36,0 \%$ & $57,2 \%$ \\
\hline
\end{tabular}

\begin{tabular}{l|c|c|c|c}
\hline Modelo & -2 Log Verosemelhança & Chi-Quadrado & gl & Sig. \\
\hline Final & 9.778 .714 & 2.821 .777 & 24 & 000 \\
\hline
\end{tabular}

Fuente: Elaboración propia. 
GLÁUCIO ARY DILLON SOARES

EN BÚSQUEDA DE LA RACIONALIDAD PERDIDA

Resultados del Modelo logístico multinomial

\begin{tabular}{l|c|c|c|c}
\hline Efecto & $\begin{array}{c}-2 \text { Log Verosemelhança } \\
\text { del Modelo Reducido }\end{array}$ & $\mathrm{X}^{2}$ & Gl. & Sig. \\
\hline Intercepto & $7.282,712$ & 0,000 & 0 &, \\
\hline TIEMPO DE RESIDENCIA en el DF & $7.294,625$ & 11,913 & 4 & 0,018 \\
\hline NIVEL SÓCIO-ECONÓMICO de la RA & $7.314,336$ & 31,624 & 4 & 0,000 \\
\hline NIVEL EDUCACIONAL & $7.381,911$ & 99,199 & 4 & 0,000 \\
\hline FACTOR 2 & $7.354,657$ & 71,945 & 4 & 0,000 \\
\hline FACTOR 1 & $8.783,351$ & $1.500,639$ & 4 & 0,000 \\
\hline NUEVOS ASENTAMIENTOS & $7.390,517$ & 107,805 & 8 & 0,000 \\
\hline
\end{tabular}

Fuente: Elaboración propia.

La principal conclusión es que la intención de voto por los principales candidatos -Roriz y Cristovam- en las elecciones de 1998, en el Distrito Federal, ha sido función, sobre todo, de la evaluación de políticas públicas hechas por el electorado. Estos resultados contrastan, de manera dramática, con los obtenidos anterioremente en otras áreas metropolitanas brasileñas, particularmente, por estudios realizados durante la dictadura.

\section{DISCUSIÓN FINAL}

¿Cómo explicar esa discrepancia? Propongo algunas posibilidades que no son mutuamente excluyentes:

- Durante la dictadura militar, las "grandes cuestiones nacionales", particularmente las políticas, como las llamó Fábio Wanderley Reis, adquirieron saliencia y prioridad indiscutible. El gran objetivo de todo demócrata brasileño era salir de la dictadura. Los temas económicos que el régimen usó, durante el período del "milagro" como auto-justificación, han sido secundarios y los temas locales no han adquirido relevancia electoral. Las campañas, de derecha, centro e izquierda, eran hechas en relación a la dictadura. Algunos de los temas políticos importantes de la época no son significativos hoy, después de la redemocratización: abolir el AI-5, piedra jurídica central de la dictadura, así como la Ley Falcão, promulgada para impedir el acceso de la oposición a los medios de comunicación en las elecciones, han dejado de ser relevantes después de su abolición y con la disminución del peligro de su reedición.

- La función de las elecciones es otra. Durante la dictadura militar, el peso dado a la posibilidad de implementar o cambiar políticas públicas a través de las elecciones era pequeño. Los loci de poder no estaban en la sociedad civil ni en sus instituciones políticas, estaban en el establecimiento militar y en las instituciones de Gobierno que los militares controlaban. La función de las elecciones era simbólica -expresión del rechazo del régimen militar. 
- La Constitución de 1988 descentralizó efectivamente los recursos públicos. Gobernadores y alcaldes han tenido más recursos para implementar políticas y para "hacer" 34

- Durante la dictadura militar, la confiabilidad de las investigaciones de opinión era más baja. Podemos advertir el efecto de la represión en el rápido descenso de las preferencias y de los votos para el PDS, partido de la dictadura, sea durante la "abertura" sea después de la redemocratización. Ellas han sido clamorosamente visibles en la campaña por las Diretas-Já, que aceleró el término de la dictadura, cuando el porcentaje favorable a la elección directa del presidente de la República ha subido vertiginosamente en pocos meses. No sabemos si efectivamente ha aumentado la aprobación de las elecciones directas o si sus adeptos han perdido el miedo. Igual, la permanencia de los militares en el poder era una cuestión muy sensible. Los datos de la época demuestran que, entre la mitad y las tres cuartas partes de la población respondían que los militares deberían permanecer. ¿Qué significaba esa respuesta? ¿Un sentimiento auténtico, generalizado, o una respuesta prudente, conveniente, considerando la represión? En los últimos años, en Brasil, el porcentaje de los que preferían volver al régimen militar ha oscilado entre $15 \%$ y $25 \%$. No tengo dudas de que la parte de la población que favorece la democracia crece en la medida en que ella se establece y fructifica, pero tampoco tengo dudas de que la represión ha sido un factor importante en la determinación de la artificialidad de muchas respuestas. Entender esas diferencias colocando el período democrático como "normal" y el anterior como represivo, provocando respuestas falsas o, simplemente, ver todo y cualquier régimen como un sistema de coacciones sociales y políticas, unos más coercitivos y otros menos, es una cuestión de preferencia personal. Subrayo que, si bien es verdad que toda sociedad y sus subgrupos ejercen presiones en la dirección de la conformidad, en los regímenes no-democráticos la presión es política y policial y el precio la pagar por la no-conformidad resulta alto.

- El final de la dictadura redujo la relevancia de las grandes cuestiones políticas. Después de la redemocratización, los cambios continuos en el contexto institucional-partidario han robado algo de la relevancia que ARENA y MDB tenían. Creo que la identificación partidaria ha perdido algún poder de influir sobre el voto, pero es posible que ese poder sea recuperado con la estabilidad y con la simplificación institucional y partidaria.

- Con la disminución de las "grandes cuestiones nacionales" y la pérdida de poder de la identificación partidaria, además del final de la "Guerra Fría”, que quitó significación a las grandes cuestiones ideológicas, ha crecido, en un modelo de suma cero, la importancia de la política del "feijão com arroz"

34. Infelizmente, esos recursos adicionales han sido rápidamente comprometidos con el pago del personal activo e inactivo.

35. En ingles sería "bread and butter politics" o, todavía, "dollars and cents". 
- Brasilia es una región excepcional en Brasil debido a sus altos niveles de renta y de educación, dada su dependencia del Gobierno Federal y la importancia de las migraciones recientes, así como también es una región de peculiaridades a partir de los asentamientos urbanos y el "Entorno"36.

- El gobernador Cristovam Buarque ha hecho una campaña basada en su desempeño, en los sus programas, enfatizando las políticas públicas y los beneficios para la población. Paz en el Tránsito; Beca Escuela; Salud en el Hogar; Paz en las Calles y Presupuesto Participativo eran expresiones corrientes en los medios y en las conversaciones de la calle.

- Los principales candidatos -los que han sido para el segunda vuelta- eran el gobernador y un exgobernador. Eso hace posible la comparación entre el desempeño y las políticas públicas de los dos.

- La vinculación entre la evaluación de una política pública es exclusivamente, o casi exclusivamente con el político que la implementó. No existe transferencia de prestigio electoral (coattails effect) a otros candidatos a puestos en otros niveles (federal, municipal) y quizás tampoco a las preferencias partidarias.

Gracias a la serie de investigaciones coordinadas por varios de los mejores científicos políticos brasileños, parcialmente financiadas por la Fundación Ford, hemos acumulado buena parte del conocimiento hoy disponible sobre los procesos políticos y electorales durante el régimen militar. Algunos de esos resultados llevaron a los analistas laicos a la conclusión apresurada de que el brasileño no sabe votar, de que la cultura cívica y política brasileña es, de alguna manera, predemocrática, valorativamente inferior. Seríamos políticamente irracionales. Sin embargo, perdiendo o ganando las elecciones, no hay como abandonar la racionalidad como factor explicativo. Evidentemente, hay más de una prioridad para las diversas "racionalidades". La investigación preelectoral de 1998, en el Distrito Federal, demuestra la existencia de esa racionalidad y sugiere la presencia de fuertes efectos contextuales e institucionales para explicar las diferencias entre sus conclusiones y la herencia cognitivo-empírica que la informó. Necesitamos realizar una investigación electoral desligada de las elecciones colocando algunos controles contextuales e institucionales en el cuestionario y ahora revisar la literatura acerca de la dictadura, en un contexto libre, democrático.

\section{APENDICE I: REGRESIONES LINEARES}

Efectuamos regresiones lineares, conociendo las limitaciones de los datos. Los objetivos del análisis eran:

- Ver cuál era el poder explicativo de un modelo que, usando datos de encuestas, integraba datos de evaluaciones con datos individuales, socio-demográficos, $\mathrm{y}$ datos estructurales, en un estudio multi-level.

36. El Entorno está integrado por los municipios que colindan con el Distrito Federal y orbitan en su alrededor, aun cuando oficialmente sean municipios de los estados de Goiás y Minas Gerais. 
- Verificar hasta qué punto la intención de voto dependía de la evaluación comparada de las políticas públicas, independientemente de variables individuales y estructurales.

- Verificar cuál era el peso relativo de cada grupo de variables en la explicación de la intención de voto.

He incluido las variables presentes en las regresiones logísticas, agregando una variable interactiva, que procuraba evaluar el impacto de la condición de migrantes recientes viviendo en asentamientos creados por Roriz. He usado como variable dependiente la intención de voto con tres categorías: $1=$ Cristovam Buarque; $2=$ Otras respuestas y $3=$ Roriz $^{37}$. Este modelo tiene amplia utilidad, con una correlación múltiple de 0,66 y un $\mathrm{R}^{2}$ ajustado de 0,43. El modelo es significativo en el nivel de 0,000. Esos resultados califican el modelo como satisfactorio, considerando el valor de $\mathrm{R}^{2}$, la significación estadística y la experiencia con datos de encuestas, donde coeficientes de determinación de esa magnitud son poco frecuentes ${ }^{38}$.

Tabla vm. Regresión linear. Modelo con variables actitudinales (evaluaciones de políticas públicas), personales y estructurales con Roriz/otras respuestas como variable dependiente

\begin{tabular}{l|c|c|c|c|c}
\hline \multicolumn{1}{c|}{ MODELO } & $\begin{array}{c}\text { Beta } \\
\text { Padronizado }\end{array}$ & $\mathrm{T}$ & $\mathrm{P}$ & $\begin{array}{c}\text { Correlación } \\
\text { orden cero }\end{array}$ & Correlación parcial \\
\hline Constante & & 40,106 & 0,000 & & \\
\hline $\begin{array}{l}\text { Asentamiento creado? } \\
\text { I=sim 2=otras 3= no }\end{array}$ & 0,071 & 4,839 & 0,000 & 0,211 & 0,083 \\
\hline $\begin{array}{l}\text { Escolaridad } \\
\text { (1 la 6, 1 es baja) }\end{array}$ & 0,096 & 6,093 & 0,000 & 0,270 & 0,104 \\
\hline $\begin{array}{l}\text { Evaluación Factor 1 } \\
\text { (alto es pro-Roriz) }\end{array}$ & $-0,493$ & $-33,510$ & 0,000 & $-0,546$ & $-0,499$ \\
\hline $\begin{array}{l}\text { Evaluación Factor 2 } \\
\text { (alto es pro-Roriz) }\end{array}$ & $-0,088$ & $-6,266$ & 0,000 & $-0,092$ & $-0,107$ \\
\hline $\begin{array}{l}\text { Nivel SE de la RA } \\
\text { (Alto, Medio, Bajo) }\end{array}$ & $-0,070$ & $-4,540$ & 0,000 & $-0,224$ & $-0,078$ \\
\hline
\end{tabular}

Fuente: Elaboración propia.

El análisis del rorizismo ha sido repetido con una nueva recodificación, usando solamente las categorías Roriz/otras respuestas. Una eliminación "para tras" retira tanto el tiempo de residencia en el Distrito Federal cuanto su interacción con la clasifiación de las Ras, con base a tener o a ser un asentamiento reciente. Este modelo tiene un $\mathrm{R}^{2}$ ajustado de 0,33 .

En lo que concierne al impacto relativo de la evaluación comparada de las políticas públicas, creemos que el instrumento más adecuado, en ese tipo de regresión (linear),

37. El lector metodológicamente sofisticado percibirá que el uso de regresiones lineares, tipo OLS, con esos datos no es "conservador", porque supone un poder de medida que algunas de las variables del modelo no ofrecen.

38. Regresiones raramente son usadas en las ciencias políticas y sociales en Brasil. VON METTENHEIM (1995: 176) ha usado la evaluación del desempeño del Ejecutivo, la percepción de políticas sociales y la percepción de políticas económicas en un modelo con un $\mathrm{R}^{2}$ ajustado de 0,17 . 
es el coeficiente padronizado Beta. La padronización es necesaria porque las variables independientes tienen escalas, desvíos padrones y medias muy diferentes. El Factor 1, de evaluación comparada de las políticas públicas, es la variable más importante en la determinación de la intención de voto, con un coeficiente Beta más de cinco veces más alto que la segunda, que también es un score factorial (Factor 2) derivado del análisis de componientes principales de las evaluaciones comparadas.

Las demás variables se comportaron de acuerdo con la expectativa de los analistas políticos locales: la intención de voto por Roriz aumenta si la Región Administrativa ha sido creada como asentamiento, y se correlaciona negativamente con la escolaridad y con el nivel socioeconómico de la Región Administrativa. Roriz es el candidato de los asentados de menos educación que viven en las regiones más pobres.

$\mathrm{El}$ análisis de correlaciones demuestra que el Factor 1 resulta poco afectado cuando pasamos de correlaciones de orden cero para correlaciones parciales, entre residuos $(0,55$ para 0,50); el Factor 2 es ayudado por ese cambio y las demás variables pierden parte de su poder de explicación ${ }^{39}$.

\section{BIBLIOGRAFIA}

AVELAR, Lucía. O Segundo Electorado. Campinas: Editora de la UNICAMP, 1989.

WANDERIEY ReIs, Fábio. Classe social e opção partidária: as eleições de 1976 em Juiz de Fora. En WanderLey Reis, Fábio (org.). Os partidos e o regime. São Paulo: Símbolo, 1978.

FERREIRA, Adir Luiz y VALE SOUSA, Margarete F. A democracia brasileira numa cultura política estudantil. En BAQUERO, Marcello (org.). Condicionantes da consolidação democrática: ética, midia e cultura política. Rio Grande do Sul: Editora da Universdade, 1996.

MoIsÉs, José Álvaro. Democratization and political culture. En D'ALVA G. KInZo, Maria (org.). Brazil: the challenges of the 1990's. London: The Institute of Latin American Studies, The University of London, 1993.

LAMOUNIER, Bolivar. Presidente Prudente: o crescimento da oposição num reduto arenista. En WANDERLEY ReIS, Fabio (org.). Os partidos e o regime. São Paulo, Símbolo, 1978.

LiMA JUNIOR, Olavo Brasil de. Articulação de interesses, posição socioeconômica e ideologia: as eleições de 1976 em Niterói. En WANDERLEY REIS, Fábio (org.). Os partidos e o regime. São Paulo, Símbolo, 1978.

MusZYNSKI, Maria Judith de Brito. Os eleitores paulistanos em 1986: a marca do oposicionismo. En: SADEK, Maria Tereza; SoUSA, M. T. S. R.; FERRARI, Levi Bucalem; da CosTA, Vicente; Muszynski, M. Judith; Kinzo, Maria D’Alva y MenEGuello, Raquel. Eleições de 1986. 1. ${ }^{a}$ ed. São Paulo: Editora Vértice, v. 01, 1989.

39. Hay que atentar a la dirección de la codificación de las variables (considerando que Roriz= 0 y-no Roriz=1): la educación ha sido codificada de menor para mayor, consecuentemente se correlaciona positivamente con la intención de voto no-Roriz; ya el nivel socioeconómico de los asentamientos ha sido codificado de mayor para el menor, correlacionándose negativamente con la intención de voto no-Roriz. 
TRINDADE, Hélgio y CEw, Judson de. Confrontação política e decisão eleitoral: as eleições municipais de 1976 em Caxias do Sul. En WaNDERLEY ReIs, Fábio (org.). Os partidos e o regime. São Paulo: Símbolo, 1978.

Von MetTenheim, Kurt. The Brazilian voter. Pittsburgh: University of Pittsburgh Press, 1995. 